\title{
Pré-Iniciação Científica em Psicologia: Contribuição para a Formação Científica no Ensino Médio
}

\author{
Gustavo Martineli Massola \\ Universidade de São Paulo, São Paulo, SP, Brasil. \\ Alessandra Blengini Mastrocinque Martins \\ Centro Paula Souza, São Paulo, SP, Brasil.
}

\author{
Bernardo Parodi Svartman \\ Universidade de São Paulo, São Paulo, SP, Brasil. \\ Luis Guilherme Galeão-Silva \\ Universidade de São Paulo, São Paulo, SP, Brasil.
}

Alessandro de Oliveira dos Santos

Universidade de São Paulo, São Paulo, SP, Brasil.

\begin{abstract}
Resumo: O objetivo desta pesquisa foi estudar as relações entre participação política e enraizamento territorial entre moradores de um Quilombo do Vale do Ribeira (SP). Esta pesquisa foi desenvolvida junto ao Programa de Pré-Iniciação Científica da Universidade de São Paulo, almejando que estudantes de escolas técnicas públicas daquela região desenvolvessem um projeto de pesquisa completo, de forma a contribuir com a sua formação científica. Durante o programa (que durou um ano), os alunos participaram de todas as etapas da pesquisa: desde a formulação inicial das questões investigadas até a apresentação da pesquisa às lideranças comunitárias, visitas à comunidade para realização de observações e entrevistas, interpretação dos dados colhidos e devolutiva dos dados à comunidade. Alunos e professores puderam refletir sobre as relações entre escola e comunidades tradicionais da região e obtiveram uma melhora significativa nas atividades pedagógicas. Conclui-se pelo valor formativo da inserção da Psicologia na grade curricular do Ensino Médio, tanto pelas possibilidades interdisciplinares que apresenta quanto por favorecer reflexões sobre a relação entre o indivíduo participante, sua escola e o entorno físico, social e cultural.
\end{abstract}

Palavras-chave: Psicologia Ambiental, Quilombo, Apego ao Lugar, Ensino Médio.

\section{Scientific Pre-Initiation in Psychology: Contribution to Scientific Education in High Schools}

\begin{abstract}
This article aimed to study the relationship between political participation and territorial rooting among residents of a Quilombo located at the Ribeira Valley area (SP). The project was carried out within the Scientific Pre-Initiation Program of the University of São Paulo, and aimed to facilitate students of technical education in public schools to develop a complete research project, thus contributing to their scientific studies. During the program (that lasted for 12 months), students participated in all stages of the research: from the initial formulation of the issues investigated to the presentation of the project to the community leaders, including community visits to perform observations and interviews, interpretation of the data collected, and a final visit to the community in order to present the research results. Students and teachers were able to reflect about the relationship between the school and traditional communities in the region and achieved a significant improvement in educational activities. We conclude that the inclusion of Psychology in the high school curriculum has a formative value, both for the interdisciplinary possibilities that it presents as for the reflections on the relationship between the participants, their school and their physical, social and cultural environment that it favors. Keywords: Environmental Psychology, Quilombo, Place Attachment, High Schools.
\end{abstract}




\title{
Pre-Iniciación Científica en Psicología: Contribución para la Formación Científica en la Educación Media
}

\begin{abstract}
Resumen: El objetivo de este artículo fue estudiar la relación entre la participación política y el arraigo territorial entre los residentes de un Quilombo ubicado en el área del Valle de Ribeira (Brasil, São Paulo). Este proyecto fue desarrollado dentro del Programa de Pre-Iniciación Científica de la Universidad de São Paulo, y tuvo por objeto facilitar a los estudiantes de escuelas públicas técnicas el desarrollo de un proyecto de investigación completo, contribuyendo así a sus estudios científicos. Durante el período del programa (que duró un año), los estudiantes participaron en todas las etapas de la investigación: desde la redacción de las cuestiones investigadas, hasta la presentación de la investigación a los líderes de la comunidad, incluyendo visitas a esta para realizar observaciones y entrevistas, así como la interpretación de los datos recogidos y la devolución de los resultados a la comunidad. Estudiantes y profesores fueron capaces de reflexionar sobre la relación entre escuela y comunidades tradicionales de la región, y han logrado una mejora significativa en las actividades educativas. Llegamos a la conclusión de que la introducción de Psicología en el currículo de las escuelas secundarias tiene un valor educativo, tanto por las posibilidades interdisciplinarias que presenta, como por el favorecimiento de la reflexión sobre la relación entre el individuo participante, su escuela y el entorno físico, social y cultural.
\end{abstract}

Palabras clave: Psicología Ambiental, Quilombo, Apego al Lugar, Escuela Secundaria.

\section{Introdução}

O presente trabalho estudou as relações entre participação política e enraizamento territorial em moradores da comunidade quilombola do Ivaporunduva, localizada na região do Vale do Ribeira, sudoeste do Estado de São Paulo, no âmbito do projeto Identidade, território e participação, realizado entre setembro de 2011 e agosto de 2012. Sua propositura e realização deram-se sobre o pano de fundo do Programa de Pré-Iniciação Científica da Universidade de São Paulo (Pré-IC) e, como tal, seu objetivo fundamental era permitir que estudantes do ensino médio técnico (EMT) de escolas públicas daquela região desenvolvessem um projeto de pesquisa completo, planejando sua realização, coletando dados, analisando-os e interpretando-os. Em outras palavras, sob esta perspectiva, o projeto visava permitir que os alunos participantes desenvolvessem conhecimento científico sobre pesquisa em Psicologia, tendo como objetivo, entre outros, contribuir para o aprimoramento de sua formação científica, considerando, por hipótese, que esta formação é generalizável para outras áreas do conhecimento.
No presente artigo são enfocados os princípios que orientaram a escolha da região e do tema, os pressupostos que motivaram os professores participantes a se engajarem neste projeto e a relação entre este projeto e o programa que o subsidiou.

\section{O Programa de Pré-Iniciação Científica}

Com o objetivo de colaborar com a qualidade da educação pública no nível do ensino médio técnico (EMT) no estado de São Paulo, foi criado o Pré-IC, que, por meio da concessão de bolsas a alunos deste nível da educação básica ${ }^{1}$, objetiva estimular sua participação em projetos de pesquisa de ponta, coordenados por professores da Universidade de São Paulo (USP). Este programa é uma iniciativa da Pró-Reitoria de Pesquisa da USP em convênio com a Secretaria de Desenvolvimento Econômico, Ciência, Tecnologia e Inovação do Estado de São Paulo, por meio de uma parceria com o Centro Paula Souza e visa oferecer oportunidades de complemento da formação pessoal, aprimoramento de conhecimentos e preparo para a vida profissional ao aluno participante. O Programa

\footnotetext{
${ }^{1}$ No caso deste projeto, todas as bolsas concedidas foram do CNPq.
} 
estimula a inserção desses alunos na USP para o acompanhamento de atividades e convivência com os procedimentos e as metodologias adotadas em pesquisa científica, o desenvolvimento de atividades científicas planejadas para o bolsista na linha de pesquisa do orientador e o acesso a outras atividades, tais como ciclos de seminários, simpósios e cursos. As bolsas de estudo tiveram duração de 12 meses e foram pagas diretamente ao estudante.

Durante o desenvolvimento da pesquisa, o aluno é acompanhado tanto pelo orientador da universidade quanto por um professor supervisor da escola de ensino médio técnico na qual está matriculado. O orientador e o supervisor devem responsabilizar-se, de formas diferentes, pela integração dos alunos junto aos programas de pesquisa em que se inserirem, pela transferência de experiências dos alunos do Programa para a escola de origem e pela frequência a ciclos de palestras promovidos pela universidade para o aperfeiçoamento do Programa e para o aprofundamento da compreensão, por parte dos alunos, do sentido de sua frequência ao mesmo. O aluno redige, ao final, um relatório circunstanciado, bem como realiza uma palestra junto a sua escola, apresentando os resultados mais significativos, em termos pessoais, de sua experiência como aluno de Pré-IC.

\section{O Ensino Médio Técnico (EMT) e o ensino de ciências}

O Ensino Médio Técnico possui as características básicas do Ensino Médio com a especificidade de formar o aluno para o trabalho técnico. Desse modo, tem como uma de suas finalidades, além da "preparação básica para o trabalho e a cidadania do educando" (Brasil, 1996 Art. 35, II), "o aprimoramento do educando como pessoa humana, incluindo a formação ética e o desenvolvimento da autonomia intelectual e do pensamento crítico" (Brasil, 1996 Art. 35, III). A realização desses objetivos pressupõe, segundo se pode depreender do texto da Lei de Diretrizes e Bases da Educação (Brasil, 1996), que a ênfase recaia, em alguma medida, sobre o ensino de ciências com vistas a permitir ao aluno que compreenda os processos de criação simbólica no âmbito científico e sua relação com a produção tecnológica.

O ensino de ciências é parte constitutiva e essencial no ensino brasileiro. A LDB estabelece que, entre as finalidades do ensino médio (normal e técnico), encontra-se "a compreensão dos fundamentos científico-tecnológicos dos processos produtivos, relacionando a teoria com a prática, no ensino de cada disciplina" (Congresso Nacional, 1996 Art. 35, IV). Mais adiante, a lei estabelece, entre outras diretrizes, que o currículo "destacará a educação tecnológica básica, a compreensão do significado da ciência, das letras e das artes" (Brasil, 1996 Art. 36, I). Por fim, ao apresentar os resultados esperados com o ensino, a lei propõe que o educando deva demonstrar "domínio dos princípios científicos e tecnológicos que presidem a produção moderna” (Brasil, 1996, Art. 36, §1o, I).

Considerando-se os parâmetros oficiais de avaliação do ensino médio (normal e técnico), pode-se concluir que os objetivos fundamentais desta etapa do processo de escolarização não têm sido alcançados. O cálculo de desempenho do ensino básico no Brasil é dado por meio do Índice de Desenvolvimento da Educação Básica (IDEB), divulgado bienalmente pelo Ministério da Educação. $O$ índice relativo ao ano de 2011, divulgado em agosto de 2012, e que em sua composição inclui o desempenho dos alunos nas disciplinas de matemática e português, indica que, em uma escala de 0 a 10, a média de desempenho dos alunos no Brasil ficou em 3,7 pontos. Em uma comparação com o ano de 2007, quando o resultado ficou em 3,5 pontos, observa-se um crescimento de 0,2 ponto em quatro anos. $\mathrm{O}$ baixo crescimento no resultado deste indicador levou o Ministério da Educação a sugerir mudanças globais na organização do currículo neste nível educacional (Takahashi, 2012). Conquanto o foco desta ação esteja direcionado para as disciplinas de matemática e português, efetivamente computadas pelo IDEB, se entendermos que o índice é representativo da situação global desse nível de ensino no Brasil, devemos assumir que situação semelhante se verifica no ensino de ciências.

No Brasil, o deficitário processo de escolarização de crianças e jovens é tipicamente associado às dificuldades encontradas para a superação de persistentes problemas sociais e para o estabelecimento de um sistema social democrático e igualitário. Ney e Hoffman (2009), por exemplo, estudando os determinantes da desigualdade social em populações rurais brasileiras, chegam à conclusão de que, "embora o capital físico seja o principal determinante da concentração da renda agrícola, é a educação o fator que explica a maior parcela da desigualdade de rendimentos nas atividades não agrícolas e no meio rural como um todo" (p. 147). 
Pode-se argumentar, por outro lado, que os problemas educacionais observados no Brasil decorrem do recente processo de massificação do ensino público, que, desde a década de 1990, passou a abranger, especialmente nos primeiros anos do ensino básico, a quase totalidade da população em idade escolar do Brasil. Rodrigues, Rios-Neto e Pinto (2011), por exemplo, analisando os indicadores demográficos e de desempenho escolar obtidos por meio do IDEB para o intervalo compreendido entre os anos de 1997 e 2005, concluem que a massificação do ensino contribui significativamente para a redução do desempenho escolar no Brasil e apontam a existência de "um trade-off entre a democratização das oportunidades educacionais e a garantia da qualidade da educação escolar" (p. 32).

Tais conclusões são contraditadas por estudos que, na esteira do pensamento de Patto (2000), combatem tanto as concepções que sustentam a vinculação entre as características da população brasileira e o seu fracasso escolar - nas formas mais arcaicas em que tais explicações encontravam seu apoio em uma suposta inferioridade racial do povo brasileiro e nas formas mais recentes, em que tais características ganhavam a denominação de "carência cultural" - quanto as concepções que veem na instituição escolar apenas uma engrenagem em um amplo maquinário de produção e reprodução de desigualdades sociais. Sem negar o papel desempenhado pela escola como aparelho ideológico do estado (Althusser, 1980), pode-se reconhecer em seu funcionamento elementos contraditórios que tanto apontam para a manutenção da desigualdade quanto para a sua superação. Neste sentido, a universalização do acesso à escola nos primeiros anos do ensino fundamental representa um passo importante para a superação das seculares formas de desigualdade e violência existentes no Brasil, a qual apresenta como contrapartida a precariedade das condições de ensino existentes nas escolas "massificadas". Carvalho (2011), ao ponderar sobre a situação do ensino no Brasil, afirma que, por décadas, "a experiência escolar conferia aos poucos que a ela tinham acesso uma distinção social que frequentemente se revertia em privilégio econômico. Com a expansão de seu atendimento à quase totalidade da população esvai-se seu poder de operar distinções e com ele o 'sentido'... que historicamente lhe foi associado" (p. 575). O próprio governo brasileiro, ao aprovar o Plano Nacional de Educação, reconhece que "a educação média é particularmente vulnerável à desigualdade social” (Brasil, 2001, p. 24).
Se considerarmos que o ensino tem como um de seus objetivos permitir aos alunos que tenham acesso à racionalidade subjacente à produção tecnológica, em outras palavras, que se tornem capazes de decodificar e produzir símbolos em conformidade com as regras adotadas pela comunidade científica, os problemas enfrentados por esta etapa escolar podem significar a impossibilidade para os alunos do acesso à forma hegemônica de produção de conhecimento nas sociedades ocidentais.

\section{O projeto Identidade, território e participação}

O projeto Identidade, território e participação elegeu como eixo de investigação a relação entre apego ao lugar e participação. Esta é uma questão que tem sido muito estudada no campo da Psicologia ambiental e da Psicologia comunitária, mas permanece como um tema que desperta polêmica na literatura especializada. Apego ao lugar é entendido como "um vínculo afetivo que as pessoas estabelecem com áreas específicas onde preferem permanecer e onde se sentem seguras e confortáveis" (Hernández, Carmen Hidalgo, Salazar-Laplace, \& Hess, 2007, p. 310) e as tentativas de conceituá-lo, compreender suas causas e consequências e, fundamentalmente, mensurá-lo, produziram um grande número de pesquisas nos últimos 20 anos. A importância deste tema pode ser lida por vários prismas, sendo um deles a recente percepção de que os lugares, considerados como um local específico que em sua expressão concreta não se iguala a qualquer outro lugar (Devine-Wright, \& Clayton, 2010), perdem crescentemente o papel que possuíam nos processos de socialização e na dinâmica social (Castells, 2007). É amplamente aceito que os lugares marcavam a vida social dos grupos humanos pré-modernos de tal forma que, de maneira geral, não se podia separar a dinâmica e a estrutura social de tais grupos dos lugares por eles ocupados. O desenvolvimento das instituições modernas levou o Ocidente a uma situação oposta, que se acentua contemporaneamente. Pode-se falar no caráter fantasmagórico dos lugares (Giddens, 1991), na existência de processos de desterritorialização (Ianni, 1997) ou na crescente dependência das regiões frente a outras regiões do globo (Santos, 1997).

Por outro lado, diversos autores atribuem importância decisiva aos lugares na formação da identi- 
dade psicossocial (Ciampa, 1990). Para Weil (1996), por exemplo, o enraizamento em uma coletividade depende de formas de participação reais, ativas e naturais, formas que vêm "automaticamente do lugar, do nascimento, da profissão, do ambiente" (Weil, 1996 p. 411, grifos nossos). Nesse sentido, podemos pensar que o apego ao lugar é uma expressão psicoafetiva do enraizamento, este último entendido como a necessidade de "participação real, ativa e natural na existência de uma coletividade que conserva vivos certos tesouros do passado e certos pressentimentos do futuro" (Weil, 1996, p.411). O conceito de enraizamento de Simone Weil articula a noção de apego ao lugar à participação e à experiência temporal das comunidades, indicando que cada uma dessas dimensões da vida social não se sustenta sem encontrar apoio nas outras duas. Bosi (1994) também ressalta a importância que o lugar desempenha na memória dos velhos, ainda que se trate de lugares já perdidos. Mesmo um sociólogo como Berger (1976) reconhece que, na psicogênese infantil, a socialização se inicia tendo como centro identitário o lar - protótipo máximo do sentido original de lugar.

O problema que esta discussão suscita pode então ser formulado de maneira sintética: ainda há apego ao lugar? Em que condições? Quais são as suas causas e suas consequências sociais e identitárias? Muitos pesquisadores supõem que o apego ao lugar é um fenômeno necessário e passam a ocupar-se de suas causas ou consequências. Uma das consequências mais estudadas da existência do apego ao lugar é a participação do indivíduo em atividades voltadas para o lugar (Devine-Wright, \& Clayton, 2010). É um pressuposto amplamente aceito o de que indivíduos que apresentam forte ligação com o lugar devem exibir comportamentos de cuidado com o lugar e participar intensamente de atividades cujo objetivo é responder exatamente a demandas locais. Com o objetivo de estudar a existência desta relação, um grande número de pesquisas quantitativas tem sido feito sobre este assunto nos últimos 20 anos (Lewicka, 2010). O grande problema com tais pesquisas é que os resultados têm sido ambíguos. Por um lado, as próprias definições de apego, lugar e participação estão abertas a discussão. Por outro, participar significa sempre participar de algo, e este algo varia desde o cuidado com o jardim até a filiação a partidos políticos. Não se pode estranhar que a relação observada entre apego ao lugar e participação varie muito de pesquisa a pesquisa, a ponto de autores como Lewicka (2010) afirmarem que "em geral, o suporte empírico para a relação positiva entre esses dois grupos de variáveis é fraco e inconsistente, e leva à necessidade de reconsiderar teoricamente esta predição de senso comum" (p. 219).

Considerando a importância do tema da participação política no contexto brasileiro posterior à década de 1980 (Sader, 1988), especialmente com a derrocada do ideal vanguardista das esquerdas brasileiras e com a crescente incorporação de organizações civis na estrutura estatal (Gohn, 2007), a investigação desta relação entre apego ao lugar, participação e enraizamento ganha outros contornos, ultrapassando sua importância teórica e mostrando-se socialmente relevante. Autores que pesquisaram o tema da participação no Brasil insinuam a importância das demandas locais no desenvolvimento de alternativas participativas (Scherer-Warren, 2002), e apontam que sua relação com as redes sociais mais amplas precisa ser melhor conhecida.

O objetivo do projeto Identidade, território $e$ participação foi, assim, o de estudar a relação entre apego ao lugar, participação e enraizamento, visando contribuir com esta discussão. Para isso, foi escolhido um fenômeno concreto - o Turismo de Base Comunitária em uma comunidade tradicional do Vale do Ribeira (SP) - que permitisse, por hipótese, compreender melhor esta relação. Este projeto foi desenvolvido em parceria com a Escola Técnica Engenheiro Agrônomo Narciso de Medeiros, localizada no município de Iguape, na região do Vale do Ribeira (SP) e fez parte de um conjunto de oito projetos desenvolvidos em parceria com duas Escolas Técnicas da região, cuja escolha prende-se a duas ordens de fatores.

Em primeiro lugar, a região do Vale do Ribeira paulista é uma área de grande potencial turístico, em virtude, entre outras coisas, de integrar a Reserva da Biosfera da Mata Atlântica criada pela UNESCO em 1991, sendo protegida por diferentes categorias de unidades de conservação. Além disso, há, na região, remanescentes de quilombos, aldeias indígenas e vilas caiçaras que ainda conservam elementos de seus modos de vida tradicional.

Em segundo lugar, apesar de seu rico patrimônio ambiental e cultural, a região apresenta os mais baixos indicadores sociais do Estado, incluindo altos índices de mortalidade infantil e analfabetismo (Sistema Único de Saúde, 2010). Além disso, a legislação ambiental rigorosa das Unidades de Conser- 
vação impõe à população local restrições em relação ao manejo da terra, o que acaba por desenhar um quadro de exclusão social no qual, especialmente para os jovens, são reservadas poucas perspectivas de trabalho ou renda.

Mas, especificamente nesta região, uma confluência de fatores, como ações de incentivo ao turismo (por exemplo, a Agenda de Ecoturismo do Vale do Ribeira, apoiada pelo Governo do Estado), iniciativas de organizações da sociedade civil (como a capacitação de monitores ambientais com vistas à ordenação da visitação dos turistas nas Unidades de Conservação), e ações de auto-organização e empreendedorismo local contribuíram para o surgimento de experiências comunitárias de organização do turismo protagonizadas por ribeirinhos, caiçaras, quilombolas e índios guaranis que podem alterar esse quadro de exclusão social. Essas experiências de desenvolvimento de modelos de turismo protagonizados pelos próprios moradores das comunidades anfitriãs têm recebido o nome de Turismo de Base Comunitária (TBC) e configuram um modelo em que os empreendedores, os gestores e os maiores beneficiários do turismo são os moradores, que, organizados de forma coletiva ou em núcleos familiares, prestam na localidade onde vivem diferentes serviços aos turistas, o que contribui para que a renda e o lucro permaneçam na comunidade e para que os atores sociais locais se envolvam de forma mais direta com tais atividades (Carvalho, 2007).

Considerando essas características locais, este projeto partiu da escolha das ações de TBC desenvolvidas por uma comunidade quilombola como fenômeno concreto de participação local e investigou suas relações com o apego ao lugar entre os moradores do quilombo Ivaporunduva. Ao fazê-lo, buscou contribuir com iniciativas de organização local, concordando com Santos (2005), para quem "mesmo nos lugares onde os vetores da mundialização são mais operantes e eficazes, o território habitado cria novas sinergias e acaba por impor, ao mundo, uma revanche" (p. 255). Em termos políticos, este trabalho procura auscultar o tipo de ação que o autor denomina "união vertical" e que implica a importância do lugar como território usado. Considerando também que o objetivo deste projeto era permitir que os alunos participantes aprendessem a desenvolver uma pesquisa empírica, coletar dados, analisá-los e interpretá-los, construindo conhecimento científico sobre um problema de ponta em Psicologia, partiu-se da hipótese de que a investigação científica deste assunto por parte de alunos permitiria ao mesmo tempo que eles desenvolvessem conhecimento socialmente relevante sobre sua região e compreendessem o processo estruturado de criação de conhecimento científico em geral.

\section{Método}

Preferimos optar por expor em conjunto os aspectos metodológicos e de resultados desta experiência por considerarmos que o desenvolvimento do método de atuação constitui por si mesmo um dos resultados esperados deste trabalho. O presente projeto fez parte de um conjunto de oito projetos desenvolvidos no âmbito do Pré-IC na região do Vale do Ribeira, dedicados a investigar diferentes características de iniciativas de TBC realizadas em um quilombo, uma aldeia guarani e uma vila caiçara. Cada projeto era orientado por um professor da Universidade de São Paulo e por um professor de uma Escola Técnica da região conveniada à universidade, e contou inicialmente com oito bolsistas, totalizando 64 alunos. As estratégias de condução das atividades foram decididas em conjunto por orientadores e supervisores, tendo sido muito semelhantes entre todos os projetos. Além disso, havia atividades obrigatórias para os participantes do Pré-IC, como participação em seminários de Pré-IC organizados pela Reitoria da USP e participação na Feira das Profissões.

Optou-se desde o início por privilegiar a participação dos alunos em todas as etapas do processo de pesquisa, permitindo, sempre que possível, que as questões a serem investigadas, os temas estudados e as tarefas definidas surgissem como decorrência do contato entre alunos e professores, privilegiando os temas em relação aos quais os próprios alunos demonstrassem interesse. Nas reuniões com os alunos, foi feito o levantamento dos seus interesses em relação ao projeto e à área profissional, baseado nas seguintes questões: 1 . O que eu sei sobre o Vale do Ribeira? O que nós sabemos sobre o Vale do Ribeira? 2. O que eu sei sobre o Quilombo? 3. O que é Turismo de Base Comunitária? 4. O que nós gostaríamos de saber sobre o Quilombo?

Muitos alunos, por serem moradores da região, traziam conhecimento escolar ou empírico, sistemático ou assistemático sobre a região e partilharam suas impressões, informações e julgamentos com seus colegas. As falas dos alunos foram registradas por 
escrito e posteriormente organizadas para permitir sua análise e subsidiar os passos seguintes da pesquisa.

Após extensiva pesquisa documental, foram realizadas reuniões técnicas para discutir as informações obtidas e para sistematizar as dúvidas do grupo em relação ao Quilombo. Houve também reuniões com os coordenadores e professores da USP, em que os alunos puderam discutir e apresentar as atividades já executadas. Os bolsistas também discutiram em conjunto com os professores a relação entre as categorias fundamentais da pesquisa (território, identidade e participação) e temas levantados durante as discussões preliminares e as leituras realizadas. Cada uma das questões propostas pelos alunos foi associada a uma das categorias ou a um conjunto de categorias e foram discutidas as formas mais adequadas para a realização das coletas de dados que permitiram respondê-las. Assim, temos como exemplo o seguinte conjunto de categorias, questões e procedimentos conectados (Quadro).

Estas questões orientaram, posteriormente, a elaboração dos instrumentos utilizados para a coleta de dados na comunidade. Por fim, os alunos, durante as atividades de preparação, buscaram conceituar as categorias fundamentais da pesquisa utilizando os textos selecionados para leitura e as discussões realizadas em grupo.

O projeto previa, por razões técnicas e orçamentárias, a realização de três visitas a cada comunidade estudada: uma visita técnica de reconhecimento, uma visita para coleta de informações e uma visita para a realização de uma reunião devolutiva dos resultados da pesquisa. O primeiro encontro previa que os alunos poderiam conversar informalmente com os moradores, colher impressões iniciais sobre o contexto socioambiental e realizar, coletivamente, uma entrevista com o líder da associação comuni- tária local. Apesar de esta atividade já estar prevista desde o início da pesquisa, seu conteúdo foi decidido em conjunto com os alunos bolsistas. A partir das discussões realizadas e do levantamento documental e bibliográfico feito pelos alunos, foram elaboradas algumas diretrizes para esta observação preliminar, indicando os aspectos da vida comunitária que deveriam ser evidenciados pelos alunos. Assim, os alunos deveriam, prioritariamente: a. Identificar as pessoas (listar nomes) que poderiam ser entrevistadas; b. Observar a divisão de tarefas, funções/ocupação dos adultos, idosos, jovens, mulheres, homens e crianças; c. Observar a estrutura do bairro ou comunidade (Sede da associação de bairro, escola, áreas de lazer, saúde, limpeza, entre outros); d. Verificar a estrutura e organização do turismo no lugar (pousada comunitária, loja de artesanato, alimentação, entre outros); e. Verificar o número de pessoas que trabalham com turismo e, também, nas outras atividades produtivas (como banana, palmito) para comparação.

Essas primeiras observações permitiram aos alunos refletir sobre a mais adequada escolha dos entrevistados. Notou-se que os idosos poderiam constituir um grupo de interesse para o projeto, da mesma forma que os jovens, pois se aventou a hipótese de que foram vistos poucos jovens no Quilombo por eles preferirem trabalhar na cidade, além de permitir obter um conjunto relevante de dados sobre a comunidade que subsidiaram as discussões do grupo e orientaram a elaboração do instrumento para a realização da entrevista.

Por proposta do orientador, a distribuição inicial do grupo amostral para a realização das entrevistas foi a seguinte: a) quatro homens jovens, b) quatro mulheres jovens, c) quatro homens adultos e d) quatro mulheres

Quadro

Categorias, questões e procedimentos de coleta propostos pelos alunos.

\begin{tabular}{|c|c|c|}
\hline Categoria & Questões & Procedimentos de coleta \\
\hline \multirow[t]{2}{*}{ Identidade } & $\begin{array}{l}\text { Quais as atividades que permanecem ao longo do tempo } \\
\text { na comunidade (apresentam caráter tradicional)? }\end{array}$ & Entrevista \\
\hline & $\begin{array}{l}\text { Os jovens mantêm o interesse pela herança histórico- } \\
\text { cultural da comunidade? }\end{array}$ & Entrevista \\
\hline Identidade e Território & Qual o papel da cultura de banana para a economia? & Entrevista \\
\hline Território & $\begin{array}{l}\text { Quais são as leis ambientais que se aplicam ao território } \\
\text { do Quilombo? }\end{array}$ & Análise documental \\
\hline Território e Participação & Como se dá a divisão de tarefas entre os moradores? & Observação direta \\
\hline
\end{tabular}


adultas, considerando que idade, tempo de moradia e gênero configuravam-se como variáveis importantes para estudar o fenômeno do apego ao lugar e sua relação com as diversas modalidades de participação social. Este grupo foi distribuído de maneira igualitária entre participantes de iniciativas de turismo sustentável e não participantes. Após a primeira visita, os pressupostos subjacentes a esta seleção foram questionados pelos alunos, tendo em vista a grande influência dos líderes comunitários na organização do Quilombo, o papel pouco nítido desempenhado pelos jovens na dinâmica comunitária e a presença dos idosos nas atividades de turismo, o que não havia sido antecipado pelo grupo de pesquisa. Assim, a seleção amostral proposta pelos alunos foi a seguinte: a. Lideranças, b. Jovens, c. Pessoas que atuam diretamente com turismo, d. Idosos.

Considerando a necessidade de controlar algumas variáveis relacionadas à escolha dos entrevistados, como o gênero, decidiu-se por retomar parcialmente a distribuição amostral anterior e tentar respeitar um número paritário de homens e mulheres, incluir no grupo de adultos um número semelhante de idosos e não idosos, observar que indivíduos que trabalhavam diretamente com turismo (em contrapartida a agricultores, por exemplo, que apoiavam indiretamente esta atividade) fossem preferidos como "participantes", além de somar a este grupo de aproximadamente 16 pessoas, três lideranças comunitárias. Também foram elaborados pelos alunos quatro instrumentos para subsidiar a realização das entrevistas, voltados para os grupos eleitos: jovens, idosos, participantes de atividades turísticas e lideranças. Entrevistados que combinassem mais de uma dessas características responderiam a perguntas oriundas de mais de um instrumento. Esses instrumentos foram aplicados a colegas da própria escola pelos alunos, com o objetivo de verificar se as questões eram compreensíveis e produziam o tipo esperado de resposta, e também foram aplicados, com os mesmos objetivos, aos moradores do município de Iguape, escolhidos aleatoriamente entre transeuntes da região central da cidade. As respostas indicaram que os entrevistados eram capazes de compreender adequadamente os itens do instrumento e responder coerentemente com os objetivos da pesquisa.

As entrevistas no Quilombo foram coletadas durante uma visita ao local, com duração de dois dias, na qual o grupo de pesquisa, incluindo todos os subprojetos envolvidos (totalizando mais de 60 pessoas), hospe- dou-se na pousada gerida pela associação de moradores. Foram entrevistadas, para o presente trabalho, 18 pessoas (sendo 11 homens), com idades variando de 14 a 78 anos, ocupações variadas e tempo de permanência no Quilombo variando de seis a 78 anos.

As entrevistas foram gravadas e transcritas, ou anotadas e digitadas, para permitir a organização de um banco de dados. É importante ressaltar que foram obedecidos todos os procedimentos éticos cabíveis, incluindo a garantia de anonimato e o direito de solicitar alterações nas informações coletadas. O projeto foi submetido e aprovado em Comitê de Ética em Pesquisa como componente de um estudo maior que incluía todos os projetos denominados "Experiências de Turismo de Base Comunitária no Vale do Ribeira: um estudo psicossocial".

Para análise dos dados, os alunos foram instruídos a respeito de procedimentos de análise categorial das entrevistas (Brandão, 1994) e os aplicaram ao material coletado. A análise foi feita individualmente pelos alunos e depois coletivamente, quando os alunos se reuniram com o supervisor em algumas ocasiões para comparar as categorias que haviam sido criadas, refinar seu significado, excluir categorias ociosas e identificar outras ocorrências da categoria em diferentes entrevistas. Após organizar as informações, cada aluno, de posse do resultado total do trabalho, redigiu uma análise a respeito do que aquilo permitia saber sobre o tema estudado (relação entre enraizamento territorial em TBC), que constituiu, em termos formais, o término do trabalho.

\section{Resultados do trabalho de formação}

O objetivo fundamental deste trabalho foi aproximar estudantes do ensino médio técnico de atividades de pesquisa desenvolvidas em universidade e colaborar para que eles desenvolvessem uma compreensão mais profunda sobre a racionalidade científica que opera como produtora de verdades socialmente aceitas nas sociedades ocidentais contemporâneas. A realização deste objetivo se orientava pelo desenvolvimento de uma série de atividades intermediárias já referidas, cujo cumprimento pode ser visto como índice do sucesso relativo do projeto. Sob tal perspectiva, os resultados mostraram-se positivos, com indicações, porém, de desafios importantes que devem ser enfrentados em outros trabalhos.

Em primeiro lugar, é fundamental destacar a importância do professor supervisor vinculado à 
escola técnica. $\mathrm{O}$ supervisor planejou e acompanhou as atividades cotidianas dos alunos e foi fundamental para manter a motivação dos alunos para o trabalho. O presente trabalho mostra que um vínculo bem estabelecido com o supervisor e uma relação adequada com os alunos podem permitir a realização de iniciativas de Pré-IC mesmo em lugares distantes.

Em segundolugar, o trabalho pode ser considerado um impulsionador para o próprio desenvolvimento do supervisor. Este é um aspecto inesperado, pois não se supunha que o trabalho tivesse importância formativa para o supervisor. Além disso, esta iniciativa pareceu importante especialmente para aqueles supervisores que nunca tiveram experiência com pesquisa. Isso indica que o conhecimento do supervisor sobre o cotidiano escolar é essencial para o desenvolvimento do trabalho, superando em alguns casos a importância de sua compreensão rigorosa do método científico.

Em terceiro lugar, a frequência dos alunos às atividades propostas nos pareceu essencial. Os alunos que apresentaram menor número de faltas e que regularmente apresentavam os relatórios foram aqueles alunos que, no final do processo, apresentaram os melhores relatórios de pesquisa.

Além disso, os alunos realizaram três visitas monitoradas à USP para conhecer o campus e para a realização de reuniões com seus orientadores. Os relatos dos alunos após as visitas, especialmente após a primeira visita, mostraram que sua importância não se vinculava apenas ao seu caráter informativo. Muitos alunos jamais haviam imaginado como era um campus universitário ou haviam considerado a possibilidade de estudar em uma universidade. A experiência teve fundamentalmente um caráter vivencial, e as atividades passaram a ser planejadas com este objetivo.

O contraponto mais importante a esta lista foi o número de desistências observado em todos os projetos. O presente trabalho teve quatro desistências entre os oito alunos que o iniciaram. Todas ocorreram no último trimestre do trabalho. A generalidade do fenômeno indica não haver uma causa específica ligada ao relacionamento com o supervisor e o orientador e, ao mesmo tempo, torna sua análise relativamente complexa. Hipotetiza-se que uma parte dos alunos não tenha se identificado com as exigências da pesquisa. Assim, o grau de dedicação e responsabilidade que o projeto exigia podem ter sido decisivos para os alunos desistirem. Por outro lado, é necessário salientar que grande parte dos alunos que concluiu as atividades desejou continuar participando voluntariamente das edições posteriores do Pré-IC na escola.

Como uma consideração adicional, vale mencionar que a formatura das turmas dos alunos participantes dos oito projetos de pesquisa ocorridos no Vale do Ribeira ocorreu nas dependências do Instituto de Psicologia da USP e foi planejado ao mesmo tempo como uma reflexão sobre o alcance do Pré-IC. Também participaram do evento os familiares dos alunos e algumas lideranças das comunidades quilombola e caiçara estudadas (lideranças indígenas foram convidadas, mas um imprevisto impediu seu comparecimento). Esse evento parece ter produzido um impacto motivacional profundo nos alunos, que repercutiu em toda a escola, indicando que este pode ter sido um dos motivos para a decisão de muitos alunos de participarem como voluntários deste trabalho no ano seguinte (cada aluno só pode receber a bolsa pré-IC uma única vez).

Nesse seminário, os professores das escolas técnicas avaliaram que o Programa de Pré-Iniciação Científica tem um grande potencial para colaborar para a melhoria do ensino nas escolas. Segundo os professores, esta experiência propiciou aos alunos o aperfeiçoamento na prática da escrita, o desenvolvimento da capacidade de leitura e interpretação de texto, a comunicação interpessoal, ampliação de vocabulário e desenvolvimento do trabalho em equipe. Nesse evento, também avaliaram que o Programa terá um impacto ainda maior caso a instituição adote estratégias para incorporar os aspectos interessantes desta experiência na prática pedagógica diária, caso contrário, os aspectos positivos ficarão restritos aos alunos e professores participantes do Programa.

\section{Resultados do trabalho de pesquisa}

Um dos objetivos do projeto era permitir que os alunos ganhassem familiaridade com a racionalidade científica, por meio da atuação em um projeto de pesquisa completo. $\mathrm{O}$ resultado desejado era que os alunos mostrassem a capacidade de refletir criticamente sobre os dados coletados, à luz dos pressupostos teóricos adotados, mesmo que o resultado deste trabalho crítico se mostrasse incompleto. Apesar de não ser esperado que os alunos desenvolvessem análises mais aprofundadas sobre o material, algumas das interpretações foram muito interessantes, mostrando que eles tiveram insights sofisticados. $\mathrm{O}$ trecho a seguir foi retirado de um dos relatórios: 
Já no grupo de idosos, essa é uma das características mais fortes, pois almejam melhorias para despertar o desejo de permanência nos jovens. Esse, porém, não é um desejo que eles nutrem devido ao turismo, pois nem mesmo no momento em que citam a questão do trabalho, lembram do turismo como fonte de renda.

Percebemos que o objetivo de descobrir se o povo deste quilombo é enraizado também foi atingido, pois descobrimos que idosos são extremamente enraizados fazendo planos para o futuro, futuro do qual talvez nem participem, mas que desejam ao seu lugar de origem. Estes participam da melhoria diária do quilombo, enquanto os jovens dizem sentir falta do lugar quando estão fora (apesar de nem todos gostarem do quilombo), mas desejam partir do quilombo e sair em busca de algo melhor, o que mostra que não há um grande enraizamento desse público. Os que trabalham com turismo são enraizados, gostam do local, querem que ele cresça, porém sempre temos as exceções e uma das pessoas que trabalham com o turismo deseja que os filhos saiam do quilombo em busca de coisas melhores.

Conquanto seja muito difícil avaliar o sucesso do trabalho sob este aspecto, entendemos que apenas a observação do aluno desenvolvendo a própria atividade de pesquisa pode fornecer elementos para um julgamento mais adequado. Neste caso, alguns alunos parecem ter sido capazes de compreender como relacionar os dados empíricos aos problemas e pressupostos teóricos da pesquisa, o que indica alguma compreensão dos princípios da atividade científica.

\section{Considerações finais}

Esta pesquisa teve a pretensão de discutir uma experiência de pré-iniciação científica no estudo das relações entre participação política e enraizamento territorial em moradores da comunidade quilombola, no âmbito do projeto Identidade, território e participação. $\mathrm{O}$ foco do projeto foi contribuir para o aprimoramento da formação científica, especialmente em temas relacionados à Psicologia Ambiental, contribuindo para a sua difusão e popularização do conhecimento psicológico. O problema aqui considerado diz respeito à crescente interdependência econômica e social que marca a época atual e parece tornar os lugares específicos intercambiáveis e pouco importantes por eles mesmos. Os efeitos deste fenômeno em nível individual podem ser muito variáveis, indo desde uma atitude blasé e indiferente face aos lugares habitados até um sentimento de alienação e perdimento que, segundo Ianni (1997), marca a Psicologia do ser humano contemporâneo.

$\mathrm{O}$ projeto teve um duplo caráter de pesquisa e de intervenção, ao mesmo tempo com a comunidade e a escola participante. No que diz respeito à comunidade, o conhecimento eventualmente gerado sobre suas práticas de TBC deveria contribuir para seu aprimoramento, visando aumentar o teor de participação democrática de seus membros tanto na própria atividade quanto, indiretamente, na sociedade como um todo. No que tange à escola, além de permitir aos alunos maior conhecimento sobre sua região, visava produzir conhecimento sobre os caminhos possíveis para a criação de práticas eficazes de ensino de ciências, em parceria com os próprios professores, no momento mesmo em que tais práticas eram implantadas. As consequências deste projeto para alunos e professores indicam o valor da Psicologia no Ensino Médio. Confluem, assim, com discussões propostas pelo Sistema Conselhos e por diversas associações científicas e profissionais de Psicologia no Brasil que defendem sua presença como disciplina regular neste nível de ensino. Tal confluência se deve, em parte, a uma maneira semelhante de compreender a Psicologia neste contexto, descrita por Soligo (2010) como "uma Psicologia da compreensão, da atenção às diferenças, da escola como espaço das relações" (p. 9). Esta forma de entender e praticar o ensino de Psicologia pode ser valiosa por permitir, como procuramos mostrar, a articulação entre diferentes áreas do conhecimento e entre a escola e seu entorno físico, social e cultural. Por outro lado, esta confluência também se deve a uma forma semelhante de entender a necessidade de articular os diferentes aspectos desta presença da Psicologia, que Soligo (2010) também expressa ao discorrer sobre uma preocupação "com a dissociação entre atuação do psicólogo e a pesquisa" (p. 12). O presente trabalho buscou a articulação entre tais aspectos. Nesse sentido, pode ser considerado como um projeto de pesquisa-ação emancipatória (Lewin, 1989; Tripp, 2005).

O quadro apresentado, ademais, ganha ainda maior complexidade quando se descobre que membros da comunidade participante frequentaram a escola onde o projeto se deu, adquirindo ali sua formação em Turismo, por exemplo, e que alunos da escola tinham importantes relações afetivas com a comunidade estudada, por alguns moradores serem seus familiares. 
Tampouco consideramos neste trabalho o impacto deste conjunto de projetos na própria comunidade do Instituto de Psicologia da USP, onde produziu importantes efeitos institucionais.

Como uma pesquisa-ação, sua estrutura é fundamentalmente interativa, formada por ciclos cujas etapas se sucedem entre períodos de avaliação, aplicação e nova avaliação. Assim que este projeto se encerrou, novos projetos foram desenvolvidos. Alguns dos principais problemas encontrados no ano anterior, ligados à gestão dos recursos necessários para realizar o transporte de algumas dezenas de alunos e professores e garantir sua hospedagem em comunidades, foram equacionados de início no novo período. Ao mesmo tempo, alguns problemas na relação entre pesquisador e comunidade, cujos detalhes compõem um material para outro trabalho, passaram a constituir tema explícito de pesquisas realizadas posteriormente.

\section{Referências}

Althusser, L. (1980). Ideologia e aparelhos ideológicos do Estado (3rd ed.). Lisboa: Editorial Presença.

Berger, P. L. (1976). Perspectivas sociológicas. São Paulo, SP: Círculo do Livro.

Bosi, E. (1994). Memoria e sociedade: lembrancas de velhos (3a. ed). São Paulo, SP: Companhia das Letras.

Brandão, H. H. N. (1994). Introdução à análise do discurso. Campinas, SP: Editora da Unicamp.

Brasil (1996). Lei no 9.394, de 20 de dezembro de 1996. Estabelece as diretrizes e bases da educação nacional. Diário Oficial da União. 23 dez.

Brasil (2001). Lei no 10.172, de 9 de janeiro de 2001. Aprova o Plano Nacional da Educação e dá outras providências. Diário Oficial da União.

Carvalho, J. S. F. (2011). A produção do fracasso escolar: a trajetória de um clássico. Psicologia USP, 22(3),569-578.doi:10.1590/S0103-65642011005000023

Carvalho, V. F. (2007). O turismo comunitário como instrumento de desenvolvimento sustentável. Revista Eco Tour. Recuperado de http://www.revistaecotour.com.br/pagina $/ \mathrm{MTc} 1 \mathrm{OQ}==/$ O_turismo_comunitario_como_instrumento_de_desenvolvimento_sustentavel

Castells, M. (2007). A sociedade em rede (10a ed.). São Paulo, SP: Paz e Terra.
A tarefa derefletir sobreo ensino de ciências torna-se fundamental num momento em que a produção econômica é alavancada pela inovação tecnológica, que demanda vultosos recursos investidos em pesquisa e a contratação de profissionais altamente especializados. O crescimento econômico dirige a atenção do capital para territórios nos quais não havia, até há pouco tempo, interesse imediato. Grandes cadeias de ensino têm sido criadas de forma a despertar suspeitas fortes de precarização de áreas sensíveis do ensino. A criação de estratégias de ensino que visem à manutenção das desigualdades mostra-se um perigo iminente. Mas parece haver muitos caminhos abertos para aqueles interessados em criar formas emancipatórias de educação. Tais caminhos exigem atenção, dedicação e preparação constantes. É imprescindível uma capacidade de análise contextual apurada e a coragem de mudar rumos de trabalho quando se mostrem inadequados.

Ciampa, A. (1990). A estória do Severino e a história da Severina (2a ed.). São Paulo, SP: Brasiliense.

Devine-Wright, P., \& Clayton, S. (2010). Introduction to the special issue: place, identity and environmental behaviour. Journal of Environmental Psychology, 30(3), 267-270. doi:10.1016/S0272-4944(10)00078-2

Giddens, A. (1991). As consequências da modernidade (5a. ed.). São Paulo, SP: UNESP.

Gohn, M. (2007). Teoria dos movimentos sociais: paradigmas clássicos e contemporâneos (6a. ed.). São Paulo, SP: Loyola.

Hernández, B, Carmen Hidalgo, M, Salazar-Laplace, ME, \& Hess, S. (2007). Place attachment and place identity in natives and non-natives. Journal of Environmental Psychology, 27(4), 310-319. doi:10.1016/j.jenvp.2007.06.003

Ianni, O. (1997). A sociedade global (5a. ed.). Rio de Janeiro, RJ: Civilização Brasileira.

Lewicka, M. (2010). Place attachment: How far have we come in the last 40 years? Journal of Environmental Psychology, 31(3), 207-230. doi:10.1016/j.jenvp.2010.10.001

Lewin, K. (1989). Experimentos com espaço social. In G. W. Lewin (Ed.), Problemas de dinâmica de grupo (4a. ed., pp. 87-99). São Paulo, SP: Cultrix.

Ney, M. G., \& Hoffman, R. (2009). Educação, concentração fundiária e desigualdade de rendimentos no meio rural brasileiro. Revista de Economia e Sociologia Rural, 47(1), 147-182.doi:10.1590/S0103-20032009000100006 
Patto, M. H. S. (2000). A produção do frasso escolar: histórias de submissão e rebeldia. São Paulo, SP: Casa do Psicólogo.

Rodrigues, C. G., Rios-Neto, E. L. G., \& Pinto, C. C. D. X. (2011). Diferenças intertemporais na média e distribuição do desempenho escolar no Brasil: o papel do nível socioeconômico, 1997 a 2005. Revista Brasileira de Estudos da População, 28(1), 5-36. doi:10.1590/S0102-30982011000100002

Sader, E. (1988). Quando novos personagens entraram em cena: falas e lutas dos trabalhadores da Grande São Paulo (1970-80). São Paulo, SP: Paz e Terra.

Santos, M. (1997). Espaço e método. São Paulo, SP: Nobel. Santos, M. (2005). O retorno do território. Observatorio Social de América Latina, 6(16), 255-61. Recuperado de http://www.hechohistorico.com.ar/Trabajos/Osal/osal/osal16/org/D16Santos.pdf

Scherer-Warren, I. (2002). Movimentos sociais e participação. São Paulo, SP: FAPESP.

Sistema Único de Saúde. (2010). DATASUS - Banco de dados do Sistema Único de Saúde (SUS). Retrieved November 28, 2010, from http://www. datasus.gov.br

Soligo, A. (2010). Psicologia no Ensino Médio: reflexões em torno da formação. In Conselho Regional de Psicologia de São Paulo (Org.), Ensino de psicologia no nível médio: impasses e alternativas (pp. 9-12). São Paulo: CRP-SP.

Takahashi, F. (2012, 16 de agosto). MEC vai propor a fusão de disciplinas do ensino médio. Recuperado de http://wwwl.folha.uol.com.br/educacao/ 1138074-mec-vai-propor-a-fusao-de-disciplinas-do-ensino-medio.shtml

Tripp, D. (2005). Pesquisa-ação: uma introdução metodológica. Educação e Pesquisa, 31(3), 443-466. doi:10.1590/S1517-97022005000300009

Weil, S. (1996). O desenraizamento. In Ecléa Bosi (Ed.), A condição operária e outros estudos sobre a opressão (pp. 407-440). Rio de Janeiro, RJ: Paz e Terra.

\section{Gustavo Martineli Massola}

Universidade de São Paulo, São Paulo-SP. Brasil.

E-mail: gustavomassola@usp.br

\section{Bernardo Parodi Svartman}

Universidade de São Paulo, São Paulo-SP. Brasil.

E-mail: bernardo@usp.br

Alessandra Blengini Mastrocinque Martins

Centro Paula Souza, São Paulo-SP. Brasil.

E-mail: alemastro@ig.com.br

Luis Guilherme Galeão-Silva

Universidade de São Paulo, São Paulo-SP. Brasil.

E-mail: lggaleao@gmail.com

Alessandro de Oliveira dos Santos

Universidade de São Paulo, São Paulo-SP. Brasil.

E-mail: alos@usp.br

Endereço para envio de correspondência:

Universidade de São Paulo, Instituto de Psicologia, Departamento de Psicologia Social e do Trabalho. Av. Prof. Mello Moraes, 1721 - Bloco A, sala 145. Cidade Universitária CEP: 5508030

São Paulo - SP

Brasil

Recebido 30/08/2014

Reformulação 15/10/2015

Aprovado 08/08/2016

Received 08/30/2014

Reformulated 10/15/2015

Approved 08/08/2016

Recibido 30/08/2014

Reformulado 15/10/2015

Aceptado 08/08/2016 
Psicologia: Ciência e Profissão Jul/Set. 2016 v. 36 n³, 558-570.

Como citar: Massola G. M., Svartman, B. P., Martins, A. B. M., Silva, L. G. G., \& Santos, A. O. (2016). Pré-iniciação científica em psicologia: contribuição para a formação científica no ensino médio. Psicologia: Ciência e Profissão, 36(3): 558-570. doi:10.1590/1982-3703001262014

How to cite: Massola G. M., Svartman, B. P., Martins, A. B. M., Silva, L. G. G., \& Santos, A. O. (2016). Scientific pre-initiation in psychology: contribution to scientific education in high schools. Psicologia: Ciência e Profissão, 36(3): 558-570. doi:10.1590/1982-3703001262014

Cómo citar: Massola G. M., Svartman, B. P., Martins, A. B. M., Silva, L. G. G., \& Santos, A. O. (2016). Pre-iniciación científica en psicología: contribución para la formación científica en la educación media. Psicologia: Ciência e Profissão, 36(3): 558-570. doi:10.1590/1982-3703001262014 